\title{
A Case of Fatal Asphyxia by a Barbell during a Bench Press
}

\author{
Risa Bandou (D, Nozomi Idota (D), Yoshihisa Akasaka and Hiroshi Ikegaya *(i) \\ Department of Forensic Medicine, Graduate School of Medical Science, Kyoto Prefectural University Medicine, \\ Kyoto 602-8566, Japan; risa1127@koto.kpu-m.ac.jp (R.B.); idotan@koto.kpu-m.ac.jp (N.I.); \\ akasaka@koto.kpu-m.ac.jp (Y.A.) \\ * Correspondence: ikegaya@koto.kpu-m.ac.jp; Tel.:+81-75-251-5343
}

check for updates

Citation: Bandou, R.; Idota, N.; Akasaka, Y.; Ikegaya, H. A Case of Fatal Asphyxia by a Barbell during a Bench Press. Forensic. Sci. 2022, 2, 1-6. https://doi.org/10.3390/forensicsci 2010001

Academic Editors: Bruce McCord and Francesco Sessa

Received: 19 November 2021 Accepted: 23 December 2021 Published: 24 December 2021

Publisher's Note: MDPI stays neutral with regard to jurisdictional claims in published maps and institutional affiliations.

Copyright: (c) 2021 by the authors Licensee MDPI, Basel, Switzerland. This article is an open access article distributed under the terms and conditions of the Creative Commons Attribution (CC BY) license (https:// creativecommons.org/licenses/by/ $4.0 /)$.

\begin{abstract}
The bench press is a widespread form of weight training with few scientific reports on its associated fatalities. We herein report a case of an individual performing bench press training who was found deceased in a supine position on the bench with the shaft of the barbell resting on his neck. The bench press safety bars were set at bench height. On the basis of the postmortem computed tomography imaging and the autopsy, the cause of death was determined to be fatal traumatic asphyxia caused by a cervical compression. We wish to highlight the importance of correctly using safety devices during weight training as well as the need for developing and disseminating safe equipment that is not dependent on the manner of use. We also wish to highlight the need for a form of legal regulation on the design of devices.
\end{abstract}

Keywords: barbell; bench press; traumatic asphyxiation; weight training

\section{Introduction}

A bench press is a type of weight training that exercises the upper body. It involves assuming a supine position on a bench, gripping a barbell with the hands spaced slightly wider than the width of the shoulders, lowering it over the chest, and then pressing it upwards with both arms whilst focusing on the pectoralis major muscles. It has also become well-known from competitions that measure the heaviest barbell that a person can lower to the chest level and then raise with the elbows fully extended. In recent years, there has been a rise in the number of people who use weightlifting as a form of fitness [1]. Although the bench press is one of the components of powerlifting competitions, there are also a number of competitions dedicated solely to it. The bench press primarily works the pectoralis major, triceps, and anterior deltoids and has been reported to be an effective training method for hypertrophy of the chest and arms [2].

As there are few studies on the fatalities associated with the use of a bench press, we report herein a case of fatal traumatic asphyxiation by a barbell shaft on an individual performing a bench press.

\section{Case}

A 55-year-old male weight training instructor was performing bench press training in a private gym outside a main house building one morning (Figure 1). His mother, who was in the main building, became suspicious when he did not answer his phone; she proceeded to the room, unlocked the exterior door, and went inside. She found him deceased, lying back on the bench with the barbell shaft resting on his neck. The safety bars attached to both sides of the bench to prevent the barbell shaft from dropping onto the body were set below the body of the deceased at the same height as the bench. The total weight of the loaded barbell was $180 \mathrm{~kg}$ comprising $160 \mathrm{~kg}$ in weights and a bar weight of $20 \mathrm{~kg}$. Although the bar was loaded with equal weights on both sides, the left side was slightly lower when found. He was in a healthy state and had no medical history. A forensic autopsy was performed $26 \mathrm{~h}$ after the deceased was found to determine the cause of death. 


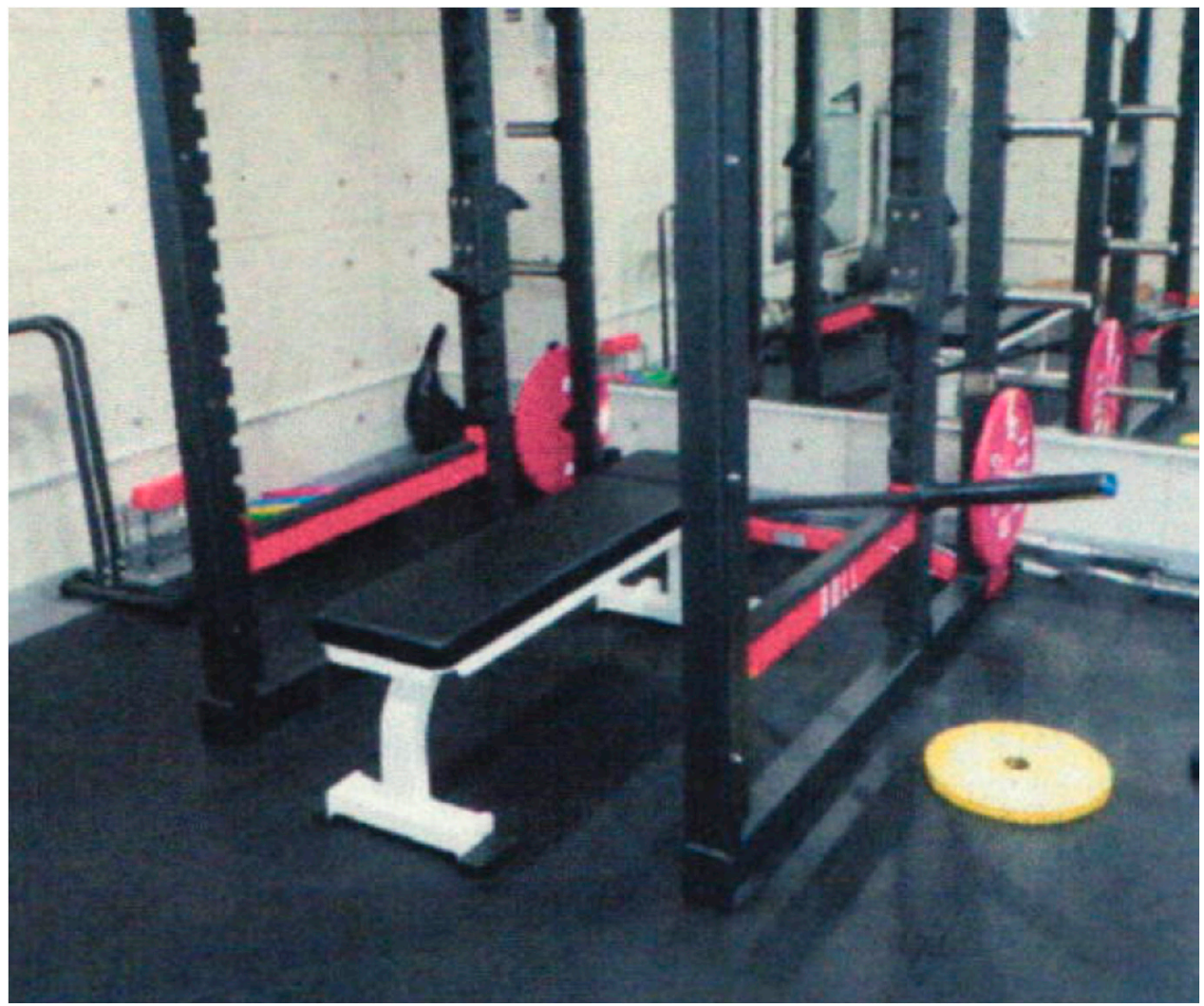

Figure 1. The training room.

In a postmortem computed tomography (CT) scan obtained before the autopsy, a vertical fracture line was found at the center of the thyroid cartilage; the thyroid cartilage itself had been flattened but no other significant findings were observed (Figure 2). In the autopsy, a band of pale discoloration with a length of $9.0 \mathrm{~cm}$ and a width of $2.5 \mathrm{~cm}$ was observed in the horizontal direction at the anterior cervical region (Figure 3) and minor subcutaneous bleeding was found in the same area. We found a collection of blood in the inferior portion of the right sternohyoid muscle and the superior portion of the left sternothyroid muscle, bleeding between the anterior surface of the left thyroid cartilage and the superior portion of the left sternothyroid muscle, and a decollement of $3.0 \mathrm{~cm}$ in diameter (Figure 4). We observed bleeding around the left superior corner of the thyroid cartilage, a vertical fracture slightly left of the center of the thyroid cartilage, bleeding at the medial mucosa of the epiglottis, and a crushing injury to the smooth muscle. Other than the findings suggestive of fatal asphyxiation (such as conjunctival petechiae, dark-red cardiac blood with an increased fluidity, and visceral congestion), no other significant injuries or lesions were found in the organs. The drug and alcohol testing results were negative.

On the basis of the above findings, we concluded that the front neck of the deceased was compressed between the fallen $180 \mathrm{~kg}$ barbell and the bench, causing insufficient ventilation due to the compression and obstruction of the respiratory tract, which resulted in death due to acute mechanical asphyxia. 


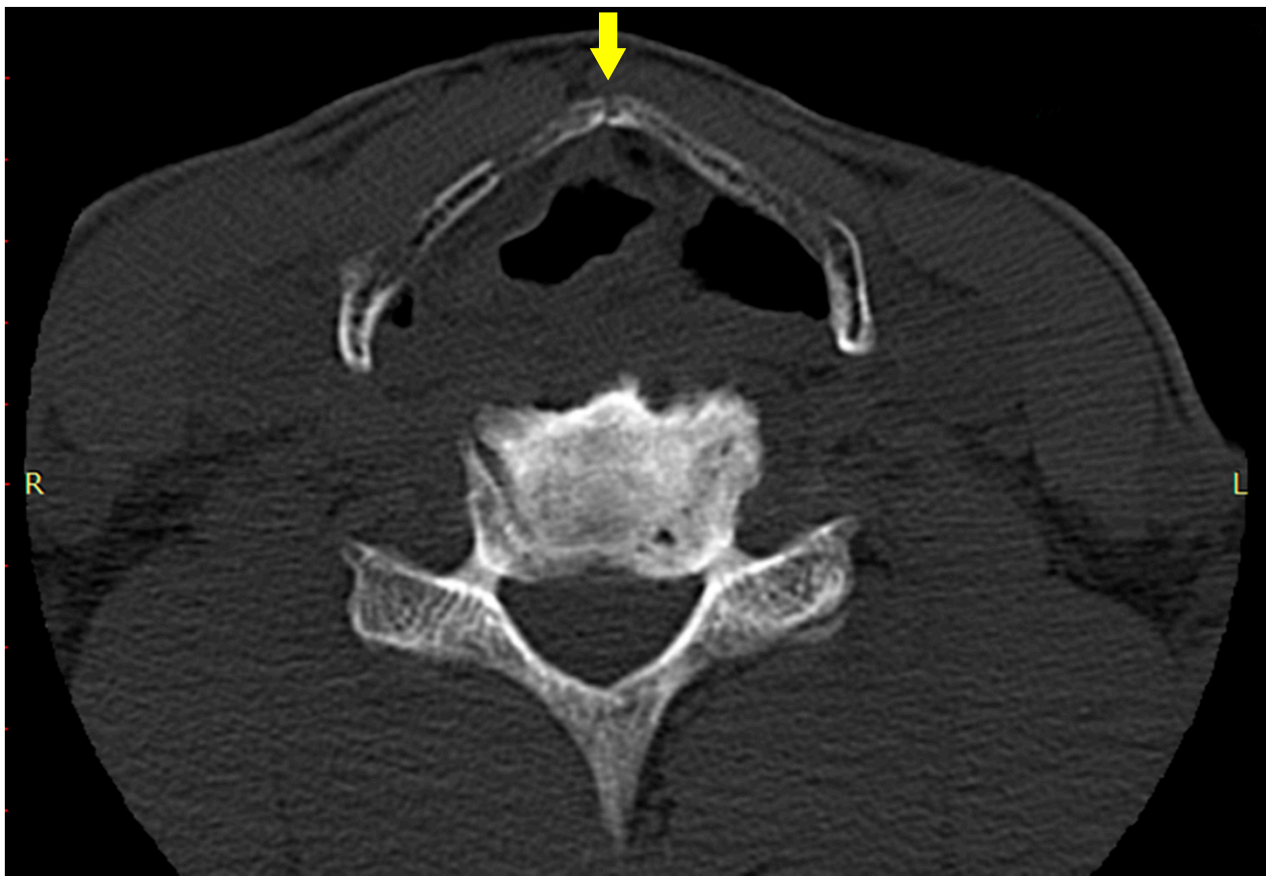

Figure 2. Cervical CT image. The thyroid cartilage appears flattened. The yellow arrow indicates the fracture site.

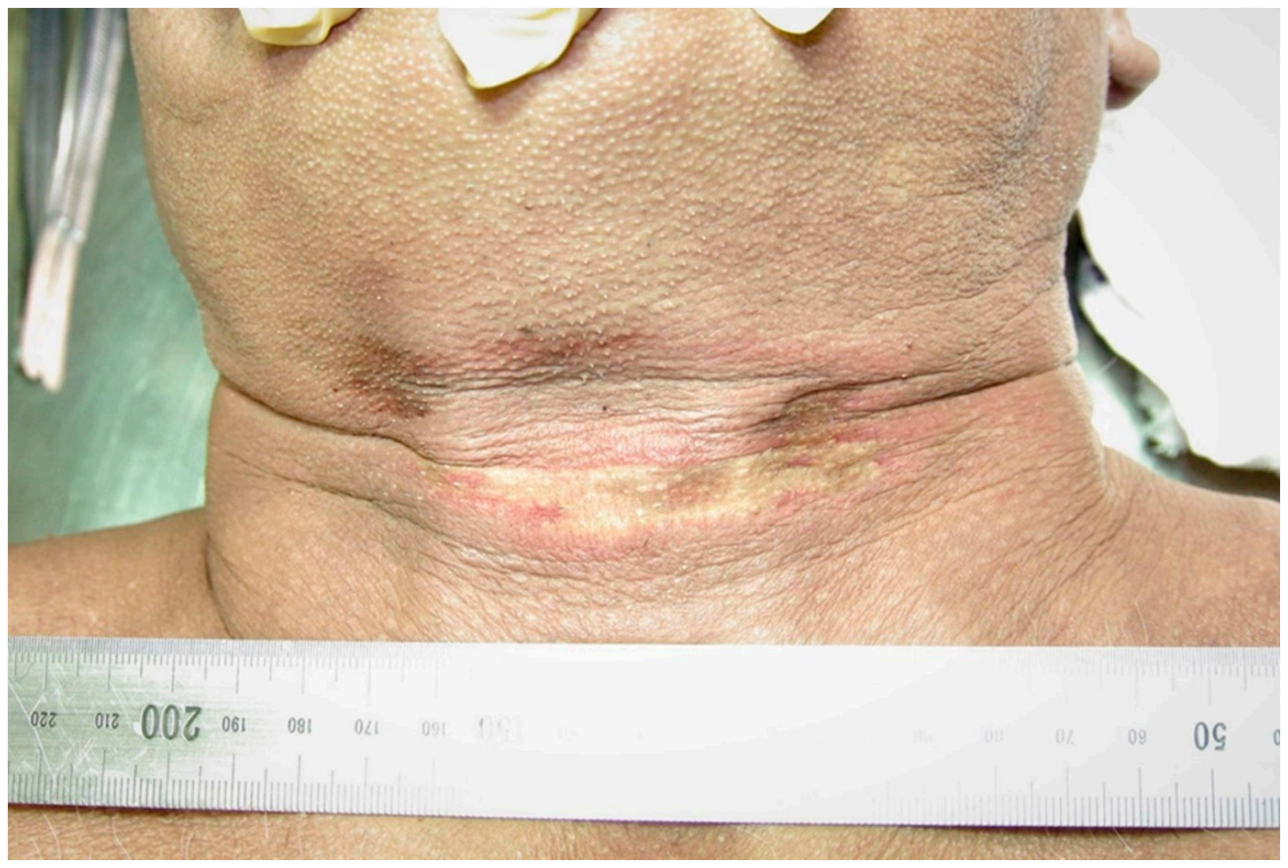

Figure 3. Discolored area at the center of the anterior cervical area. We found a band of pale discoloration measuring $9.0 \mathrm{~cm}$ in length and $2.5 \mathrm{~cm}$ in width in the horizontal direction at the anterior cervical region. 


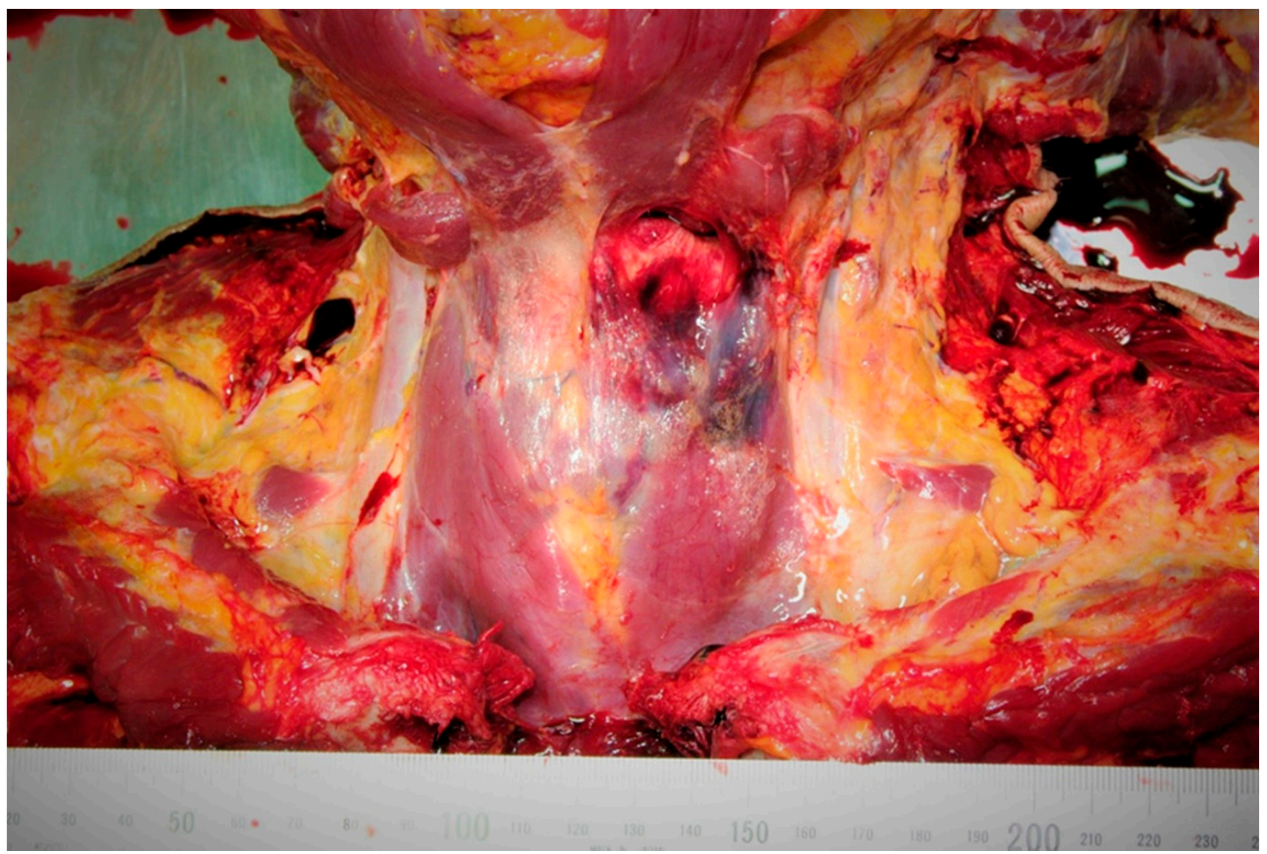

Figure 4. Bleeding in the muscle layer of the neck. We found bleeding between the anterior surface of the left side of the thyroid cartilage and the superior portion of the left sternothyroid muscle, as well as a decollement of $3.0 \mathrm{~cm}$ in diameter.

\section{Discussion}

In recent years, the increased popularity of fitness has led to a concomitant increase in the rate of injuries related to powerlifting and weightlifting [3,4]. However, the injury rates among elite powerlifters, such as the deceased in our case, are not necessarily particularly high [5-7]. A large portion of such incidents (25-50\%) involves injuries to the arms, chest, and back muscles and the percentage of neck injuries is considered to be low $(0-16 \%)[4,8-14]$. However, when the bench press alone is considered, the injury sites differ. According to the estimates based on a sampling survey conducted by the Consumer Product Safety Commission (CPSC) in the US of 3820 injuries that were sustained in connection with a bench press in $2002,53 \%$ were face or neck injuries and $42 \%$ were chest injuries [15]. The main reason for requiring urgent outpatient care was the loss of control of the barbell during a bench press. In addition, according to the CPSC, there were 20 fatalities associated with weight training from 1999 to 2002, of which at least 14 were due to asphyxiation, 12 were associated with a bench press, and four were fatal asphyxiation due to a cervical compression [15]. During a bench press, there is a risk of the barbell or weights falling onto the neck or chest of the lifter when the muscles in the chest and arm become fatigued $[13,14,16,17]$. This may lead to the compression of the respiratory tract, resulting in fatal asphyxiation [10]. To date, no paper on fatalities caused by a bench press has been published in Japan [18]. Only one report (discussing two cases) has been published overseas [16]. The two cases reported by Jumbelic involved a total barbell weight of 425 pounds (approximately $193 \mathrm{~kg}$ ) and 72.6 pounds (approximately $33 \mathrm{~kg}$ ), respectively, and neither of these cases involved the use of safety bars. An autopsy was performed in both cases; the causes of death were determined to be fatal traumatic asphyxiation due to a cervical compression. The present case was subjected to a postmortem CT scan and autopsy. Although the cause of death was determined to be asphyxiation due to a cervical compression, the circumstances warranted the avoidance of an assumption of traumatic asphyxiation. Therefore, an autopsy was necessary to ascertain the cause of death in addition to the cause of the weights dropping onto the cervical region.

ASTM International (ASTM F1749) has issued general warnings for fitness equipment as well as voluntary standards indicating safety signs for established facilities with the goal 
of understanding the appropriate methods for using equipment [19]. To safely use a bench press, the presence of a spotter who can lift the barbell to prevent it from falling onto the neck or chest if the muscles of the lifter reach their limit is recommended; there are also a number of products that can increase safety when exercising alone [20]. However, the general warnings on fitness equipment today are extremely vague [21] and are, therefore, insufficient for preventing accidents [13]. In addition, one might expect that contemporary fail-safe mechanisms would prevent accidents [22]; however, if the user is only vaguely aware of safety, such an individual would ultimately not observe these warnings and accidents cannot be prevented.

In the future, as the number of individuals engaging in weight training increases, these types of accidents are expected to rise. Therefore, we believe that there is an urgent need to develop and disseminate fail-safe mechanisms that are not dependent on the manner of use by the user (e.g., designing safety bars so that they cannot be lowered as far as the bench height) and to establish a form of legal regulation on the design of devices.

Author Contributions: Investigation, R.B.; writing—original draft preparation, R.B.; writing—review and editing, N.I.; visualization, Y.A.; supervision and project administration, H.I. All authors have read and agreed to the published version of the manuscript.

Funding: This research received no external funding.

Institutional Review Board Statement: Not applicable.

Informed Consent Statement: Not applicable.

Data Availability Statement: Not applicable.

Conflicts of Interest: The authors declare no conflict of interest.

\section{References}

1. National Sporting Goods Association. Sports Participation-Series I and II; Annual Report 2018; National Sporting Goods Association: Mount Prospect, IL, USA, 2006; Available online: https:/ /www.nsga.org/globalassets/products/product-images / single-sport-participation-2018-edition---example.pdf (accessed on 24 December 2021).

2. Pickett, T.C.; Lewis, R.J.; Cash, T.F. Men, muscles, and body image: Comparisons of competitive bodybuilders, weight trainers, and athletically active controls. Br. J. Sports Med. 2005, 39, 217-222. [CrossRef] [PubMed]

3. Yu, J.S.; Habib, P.A. Common injuries related to weightlifting: MR imaging perspective. Semin. Musculoskelet. Radiol. 2005, 9, 289-301. [CrossRef] [PubMed]

4. Keogh, J.W.; Winwood, P.W. The epidemiology of injuries across the weight-training sports. Sports Med. 2017, 47, 479-501. [CrossRef] [PubMed]

5. Raske, R.; Nolin, R. Injury incidence and prevalence among elite weight and power lifters. Am. J. Sports Med. 2002, 30, 248-256. [CrossRef] [PubMed]

6. Keogh, J.; Hume, P.A.; Pearson, S. Retrospective injury epidemiology of one hundred one competitive Oceania power lifters: The effects of age, body mass, competitive standard, and gender. J. Strength Cond. Res. 2006, 20, 672-681. [CrossRef]

7. Siewe, J.; Rudat, J.; Rollinghoff, M.; Schlegel, U.J.; Eysel, P.; Michael, J.W. Injuries and overuse syndromes in powerlifting. Int. J. Sports Med. 2011, 32, 703-711. [CrossRef]

8. Wurm, M.; Imhoff, A.B.; Siebenlist, S. Surgical repair of acute pectoralis major muscle ruptures. Oper. Orthop. Traumatol. 2018, 30, 390-397. [CrossRef]

9. Kakwani, R.G.; Matthews, J.J.; Kumar, K.M.; Pimpalnerkar, A.; Mohtadi, A.P.N. Rupture of the pectoralis major muscle: Surgical treatment in athletes. Int. Orthop. 2007, 31, 159-163. [CrossRef]

10. Bengtsson, V.; Berglund, L.; Aasa, U. Narrative review of injuries in powerlifting with special reference to their association to the squat, bench press and deadlift. BMJ Open Sport Exerc. Med. 2018, 4, e000382. [CrossRef] [PubMed]

11. Calhoon, G.; Fry, A.C. Injury rates and profiles of elite competitive weightlifters. J. Athl. Train. 1999, 34, 232-238. [PubMed]

12. Winwood, P.W.; Hume, P.A.; Cronin, J.B.; Keogh, J.W. Retrospective injury epidemiology of strongman athletes. J. Strength Cond. Res. 2014, 28, 28-42. [CrossRef] [PubMed]

13. Aasa, U.; Svartholm, I.; Andersson, F.; Berglund, L. Injuries among weightlifters and powerlifters: A systematic review. Br. J. Sports Med. 2017, 51, 211-219. [CrossRef] [PubMed]

14. Strömbäck, E.; Aasa, U.; Gilenstam, K.; Berglund, L. Prevalence and consequences of injuries in powerlifting: A cross-sectional study. Orthop. J. Sports Med. 2018, 6. [CrossRef] [PubMed]

15. Stevenson, T. Denial of Petition Requesting Labeling of Weightlifting Bench Press Benches to Reduce or Prevent Deaths Due to Asphyxia/Anoxia (Petition no. CP 03-3) [Letter]; United States Consumer Product Safety Commission: Bethesda, MD, USA, 2004. 
16. Jumbelic, M.I. Traumatic asphyxia in weightlifters. J. Forensic Sci. 2007, 52, 702-705. [CrossRef] [PubMed]

17. Hooper, D.R.; Szivak, T.K.; Comstock, B.A.; Dunn-Lewis, C.; Apicella, J.M.; Kelly, N.A.; Creighton, B.C.; Flanagan, S.D.; Looney, D.P.; Volek, J.S.; et al. Effects of fatigue from resistance training on barbell back squat biomechanics. J. Strength Cond. Res. 2014, 28, 1127-1134. [CrossRef] [PubMed]

18. Kuroyanagi, K. Sudden death during sport activities. Shinzo 2006, 38, 53-60. (In Japanese) [CrossRef]

19. Trnka, J.; Gesicki, M.; Suslo, R.; Siuta, J.; Drobnik, J.; Pirogowicz, I. Death as a result of violent asphyxia in autopsy reports. Adv. Exp. Med. Biol. 2013, 788, 413-416. [CrossRef] [PubMed]

20. ASTM F 1749-9: 2009 Specification for Fitness Equipment and Fitness Facility Safety Signage and Labels; American Society for Testing and Materials: West Conshohocken, PA, USA, 2009.

21. Larson, K.; Levy, J.; Rome, M.G.; Matte, T.D.; Silver, L.D.; Frieden, T.R. Public health detailing: A strategy to improve the delivery of clinical preventive services in New York City. Public Health Rep. 2006, 121, 228-234. [CrossRef] [PubMed]

22. Robert, W. Bench Press Safety Apparatus. Strength and Safety Designs Corp a Corporation of, 1987-11-16. Available online: https:/ / patents.google.com/patent/US4799673 (accessed on 24 December 2021). 